\title{
Prevalence, sources and purpose of self-prescribed non-opioid analgesic among health professionals in Sokoto metropolis, Nigeria: a cause for concern
}

\author{
Catherine Fidelis ${ }^{1,2}$, Kehinde Kazeem Kanmodi ${ }^{2,3}$, Johnson Olajolumo ${ }^{4}$ \\ ${ }^{1}$ Department of Pharmacy, Usmanu Danfodiyo University Teaching Hospital, Sokoto, Nigeria \\ ${ }^{2}$ Cephas Health Research Initiative Inc, Ibadan, Nigeria \\ ${ }^{3}$ Community Health Officers Training Programme, Usmanu Danfodiyo University Teaching Hospital, Sokoto, Nigeria \\ ${ }^{4}$ Department of Internal Medicine, Obafemi Awolowo University Teaching Hospital, Ile-Ife, Nigeria
}

\begin{tabular}{l}
\hline ARTICLE INFO \\
\hline Received 18 November 2017 \\
Accepted 23 December 2017
\end{tabular}

\section{Keywords:}

analgesics,

self-prescription,

health professionals,

Nigeria.

\begin{abstract}
Background. Self-medication is defined as the use of medicines without a doctor's prescription. The non-opioid analgesics (NOAs) constitute one of the most commonly self-prescribed drugs globally. This study aims to determine the prevalence of NOAs self-medication, and also explore the purpose and sources of the self-prescribed NOAs among health professionals in Sokoto metropolis, Nigeria.

Methods. Data obtained from a cross-section of 205 health professionals in Sokoto metropolis, Nigeria, were used for this study. The study tool used was a well-structured questionnaire. Data analysis was done using the SPSS version 20 software.

Results. Only $36.6 \%$ of the 205 subjects were within the age range of 26 to 30 years, $38.0 \%$ were nurses. The majority (85.9\%) of the subjects had self-prescribed NOAs, of which $6.8 \%$ of them had a positive history treatment for NOA overdose. Patent medicine stores (43.0\%) were reported to be the most common source of acquisition of self-prescribed NOAs. The majority (63.9\%) of the subjects used NOAs to get relieved from headaches. Paracetamol (79.0\%) and Diclofenac (65.9\%) were the top two self-prescribed NOAs among the subjects.

Conclusion. Non-opioid analgesic self-prescription is a popular practice among health professionals in Sokoto metropolis, Nigeria. All the various routes of access (e.g. hospital pharmacy) to NOAs need to be revisited in order to curb the irrational use of NOAs in Nigerian society.
\end{abstract}

\section{INTRODUCTION}

Self-medication can be defined as the act of consuming drug(s) on one's own initiative in an attempt to relieve perceived symptoms or disease [1]. Self-medication has some associated benefits, some of which include: self-care; reduction in the frequency of visits to healthcare facilities (especially in places where medical personnel are not sufficient); and reduction in the cost and time spent in accessing health care services [2,3]. However, self-medication has some lethal risks associated with it, some of which are: overdosing; under-dosing; adverse drug reactions; and systemic toxicity [4-7]. A most widely consumed self-prescribed drug-group is that of the analgesics [8-10]. Analgesics can

\footnotetext{
* Corresponding author

e-mail: kanmodikehinde@yahoo.com
}

be broadly grouped under either the over-the-counter (OTC) drugs or the prescription-only. The OTC drugs are those medications that could be used without the physician's prescription, while the prescription-only drugs are drugs that should be consumed only when they are recommended for use by a physician [10-12]. All opioid analgesics fall strictly under the category of the prescription-only medications. However, this does not apply to all NOAs, as some NOAs are classified under the OTC medications, while the others are grouped under the prescription-only medications [12,13]. Examples of the OTC NOAs are paracetamol, ibuprofen, naproxen sodium, and the high-dose aspirin. The other NOAs (diclofenac, celecoxib, piroxicam, among others) are grouped under the prescription-only medications [10-13]. Despite the fact that some NOAs are OTC drugs and seem 
safe for general use, they should be used with strict precaution. For instance, paracetamol is an OTC NOA; its chronic use or acute overdose can cause liver failure [14].

In Nigeria, NOAs are freely available as OTC drugs, and they constitute one of the commonly self-prescribed medications among the lay Nigerian populations $[9,15]$. Health professionals are expected to be more rational in their use of NOAs as compared to the general public, since they are more medically knowledgeable than the lay populations [16]. There is also a popular directive suggesting that health professionals, particularly the doctors, should not treat themselves [17-19]. However, self-prescription of NOAs was also found to be highly prevalent among them [16-22].

To the best of the authors' knowledge, no published literature is available on the NOA self-medication practices among health professionals in Sokoto metropolis, Northwest Nigeria. This study aims to: determine the prevalence and sources of self-medication with NOAs among health professionals in the metropolitan city of Sokoto, Nigeria; and also explore the purpose behind their use of self-prescribed NOAs.

\section{MATERIALS AND METHODS}

This research was a descriptive cross-sectional study conducted among health professionals in the metropolitan city of Sokoto. The city of Sokoto is the capital of Sokoto State. Sokoto State is located in the extreme northwest of Nigeria, and it is close to the confluence of the Sokoto River and the Rima River [23].

The study tool adopted was a well-structured anonymous questionnaire developed from literature review [16-20,22,24].

Five (one private and four public) hospitals situated within the Sokoto metropolis were visited for this survey. The authors approached the study participants on a one-onone basis at the clinics, laboratories, pharmacies, wards, and offices. A total of 233 subjects volunteered to participate in this study. This research data was collected in the month of October, 2017.

Out of the 233 participants that were issued questionnaires, only 207 returned theirs. During the data cleaning stage, 2 questionnaires were discarded because they were not properly filled-out. Data analysis was done using the SPSS version 20 software. The frequency distribution of all variables were determined, the comparisons of qualitative variables were done using the Chi-square test, and a p-value $<0.05$ was considered statistically significant. The results were illustrated using tables and charts.

Approval to conduct this study was obtained from the State Health Research Ethics Committee, Ministry of Health, Sokoto State, Nigeria (Ref. No: SKHREC/068/017).

\section{RESULTS}

More than a third (38.0\%) of the subjects surveyed in this study were nursing officers (Figure 1), close to four-tenth $(36.6 \%)$ of them were within the age range of 26 to 30 years, $42.9 \%$ were from the Hausa tribe, and $30.2 \%$ had less than one year experience in medical practice (Table 1).
Table 1. Demographic profile of subjects

\begin{tabular}{|c|c|}
\hline Characteristics & Frequency (\%) \\
\hline \multicolumn{2}{|c|}{ Gender } \\
\hline Male & $130(63.4)$ \\
\hline Female & $75(36.6)$ \\
\hline \multicolumn{2}{|c|}{ Tribe } \\
\hline Hausa & $88(42.9)$ \\
\hline Yoruba & $32(15.6)$ \\
\hline Igbo & $40(19.5)$ \\
\hline Others & $45(22.0)$ \\
\hline \multicolumn{2}{|c|}{ Age (in years) } \\
\hline$<21$ & $1(0.5)$ \\
\hline $21-25$ & $31(15.1)$ \\
\hline $26-30$ & $75(36.6)$ \\
\hline $31-35$ & $56(27.3)$ \\
\hline $36-40$ & $26(12.7)$ \\
\hline $41-45$ & $7(3.4)$ \\
\hline$>46$ & $8(3.9)$ \\
\hline Not specified & $1(0.5)$ \\
\hline \multicolumn{2}{|c|}{ Year(s) of practice } \\
\hline$<1$ & $62(30.2)$ \\
\hline $1-5$ & $69(33.7)$ \\
\hline $6-10$ & $52(25.4)$ \\
\hline $11-15$ & $11(5.4)$ \\
\hline $16-20$ & $4(2.0)$ \\
\hline$>20$ & $6(2.9)$ \\
\hline Not specified & $1(0.5)$ \\
\hline
\end{tabular}

The prevalence of NOA self-medication among the subjects was very high $(85.4 \%)$, to the extent that $22(10.7 \%)$ subjects reported the use of self-prescribed NOA within the recent 7 days prior to the time of their participation in this study (Table 2). Self-medication with NOAs was found to be more common among the men and the most popular purpose of self-prescription of NOAs was for the relief of headaches (Tables 2, 3).

Paracetamol was the most commonly (79\%) reported selfprescribed OTC NOA among the subjects. As high as $65.9 \%$ of all subjects had self-prescribed diclofenac, a prescriptiononly NOA, for their personal use (Table 4).

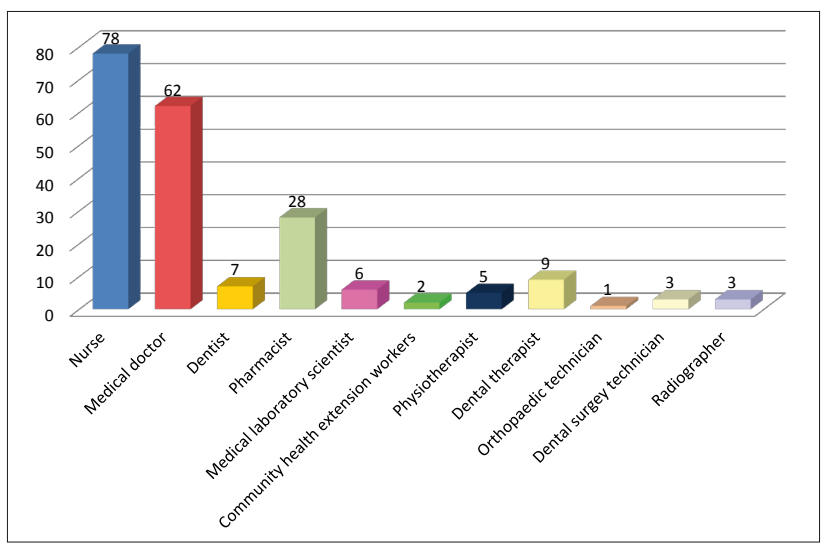

Figure 1. Professions of subjects 
Table 2. Comparison between the medical profession of subjects and their rate of NOA self-prescription

\begin{tabular}{|c|c|c|c|c|c|c|c|c|c|c|c|c|c|}
\hline Variable & Response & A & B & $\mathrm{C}$ & $\mathrm{D}$ & $E$ & $\mathrm{~F}$ & G & $\mathrm{H}$ & I & J & K & $x^{2}$ \\
\hline \multirow{3}{*}{$\begin{array}{l}\text { Have you ever used } \\
\text { a self-prescribed NOA? }\end{array}$} & Yes & 61 & 58 & 6 & 28 & 5 & 1 & 5 & 7 & 1 & 2 & 1 & \multirow{3}{*}{$\begin{array}{l}0.135 \\
d f=20\end{array}$} \\
\hline & No & 13 & 4 & 1 & 0 & 1 & 1 & 1 & 2 & 0 & 0 & 2 & \\
\hline & I can't remember & 4 & 0 & 0 & 0 & 0 & 0 & 0 & 0 & 0 & 0 & 0 & \\
\hline \multirow{5}{*}{$\begin{array}{l}\text { How often do you use } \\
\text { self-prescribed NOA? }\end{array}$} & Never & 8 & 2 & 2 & 0 & 1 & 0 & 1 & 1 & 0 & 0 & 2 & \multirow{5}{*}{$\begin{array}{l}0.082 \\
d f=40\end{array}$} \\
\hline & Rare & 15 & 22 & 1 & 6 & 0 & 1 & 4 & 2 & 0 & 0 & 0 & \\
\hline & Sometimes & 44 & 27 & 4 & 17 & 5 & 1 & 1 & 6 & 1 & 3 & 1 & \\
\hline & Usually & 3 & 10 & 0 & 4 & 0 & 0 & 0 & 0 & 0 & 0 & 0 & \\
\hline & Always & 4 & 1 & 0 & 1 & 0 & 0 & 0 & 0 & 0 & 0 & 0 & \\
\hline \multirow{5}{*}{$\begin{array}{l}\text { When was the last } \\
\text { time you self- } \\
\text { prescribed NOA? }\end{array}$} & This week & 8 & 6 & 1 & 4 & 2 & 0 & 0 & 0 & 0 & 1 & 0 & \multirow{5}{*}{$\begin{array}{l}0.246 \\
d f=40\end{array}$} \\
\hline & Last week & 13 & 5 & 2 & 6 & 0 & 0 & 0 & 1 & 0 & 0 & 0 & \\
\hline & Last month & 16 & 11 & 2 & 12 & 0 & 0 & 2 & 2 & 0 & 1 & 0 & \\
\hline & $\begin{array}{l}\text { Within the past } \\
\text { six months }\end{array}$ & 15 & 21 & 0 & 5 & 2 & 0 & 1 & 2 & 1 & 0 & 1 & \\
\hline & $\begin{array}{l}\text { More than six } \\
\text { months ago }\end{array}$ & 11 & 14 & 1 & 1 & 0 & 1 & 2 & 4 & 0 & 1 & 0 & \\
\hline
\end{tabular}

$\mathrm{A}=$ Nurse; $\mathrm{B}=$ Medical doctor; $\mathrm{C}=$ Dentist; $\mathrm{D}=$ =Pharmacist; $\mathrm{E}=$ Medical laboratory scientist; $\mathrm{F}=$ Community health extension workers; $\mathrm{G}=$ Physiotherapist; $\mathrm{H}=$ Dental Therapist; $\mathrm{I}=$ Orthopaedic technician; $\mathrm{J}=$ Dental surgery technicians; $\mathrm{K}=$ Radiographers

Table 3. Purpose of use of self-prescribed NOAs among subjects

\begin{tabular}{|l|c|c|c|}
\hline \multicolumn{1}{|c|}{ Purpose } & Male (\%) & Female (\%) & $\mathrm{X}^{2}$ \\
\hline To reduce fever & $70(53.8)$ & $37(49.3)$ & $0.490, \mathrm{df}=1$ \\
\hline $\begin{array}{l}\text { To reduce } \\
\text { inflammation }\end{array}$ & $71(54.6)$ & $27(36.0)$ & $0.038, \mathrm{df}=1$ \\
\hline $\begin{array}{l}\text { To reduce pains in the } \\
\text { joints }\end{array}$ & $70(53.8)$ & $30(40.0)$ & $0.143, \mathrm{df}=1$ \\
\hline To reduce headaches & $80(61.5)$ & $51(68.0)$ & $0.026, \mathrm{df}=1$ \\
\hline $\begin{array}{l}\text { To reduce pains } \\
\text { during menstrual flow }\end{array}$ & $\mathrm{N} / \mathrm{A}$ & $42(56.0)$ & $\mathrm{N} / \mathrm{A}$ \\
\hline $\begin{array}{l}\text { To reduce muscle } \\
\text { pain }\end{array}$ & $69(53.1)$ & $24(32.0)$ & $0.015, \mathrm{df}=1$ \\
\hline \begin{tabular}{l} 
To reduce toothache \\
\hline $\begin{array}{l}\text { Other reasons } \\
\text { e.g. malaise, pain } \\
\text { prevention. etc. }\end{array}$
\end{tabular} & $45(34.6)$ & $17(22.7)$ & $0.149, \mathrm{df}=1$ \\
\hline $\begin{array}{l}\mathrm{N} / \mathrm{A}=\text { Not Applicable } \\
\text { 2(1.5) }\end{array}$ & $2(2.7)$ & $0.196, \mathrm{df}=1$ \\
\hline
\end{tabular}

Table 4. Non-opioid analgesics that had been self-prescribed by the subjects

\begin{tabular}{|l|c|}
\hline \multicolumn{1}{|c|}{ Generic name of NOAs } & Frequency (\%) \\
\hline Ibuprofen & $128(62.4)$ \\
\hline Aspirin & $43(21.0)$ \\
\hline Diclofenac & $135(65.9)$ \\
\hline Paracetamol & $162(79)$ \\
\hline Naproxen Sodium & $14(6.8)$ \\
\hline Indomethacin & $20(9.8)$ \\
\hline Aceclofenac & $41(20.0)$ \\
\hline Celecoxib & $20(9.8)$ \\
\hline Piroxicam & $6(2.9)$ \\
\hline
\end{tabular}

The patent medicine store was the most common place $(43 \%)$ where these self-prescribed NOAs were sourced from (Table 5).

From comparisons between histories of self-prescription of NOAs with that of treatment of NOA overdose among the study subjects, it was found that those that had been treated of overdose of NOAs were its self-prescribers. Furthermore, as high as $12(6.8 \%)$ (Table 6) out of the 175 (Table 2) selfprescribers of NOAs had been treated for NOA overdose.
Table 5. Sources of procured self-prescribed NOAs among subjects

\begin{tabular}{|l|c|}
\hline \multicolumn{1}{|c|}{ Source of NOAs } & Frequency (\%) \\
\hline Community pharmacy outlet & $53(25.9)$ \\
\hline Hospital pharmacy & $63(30.8)$ \\
\hline Patent medicine stores & $88(43.0)$ \\
\hline Drug hawkers & $11(5.4)$ \\
\hline
\end{tabular}

Table 6. Comparison between histories of NOA self-prescription practices and treatment of NOA overdose among subjects

\begin{tabular}{|l|c|c|c|c|c|}
\hline & \multicolumn{4}{|c|}{ Have you ever been treated for overdose } & \multirow{2}{*}{$\mathrm{X}^{2}$} \\
\cline { 2 - 5 } & & Yes NOAs before?* & No & $\begin{array}{c}\text { I can't } \\
\text { remember }\end{array}$ & \\
\hline \multirow{2}{*}{$\begin{array}{l}\text { Have you ever } \\
\text { used a self- } \\
\text { prescribed NOAs } \\
\text { for yourself?" }\end{array}$} & Yes & 12 & 151 & 5 & \multirow{2}{*}{$0.724, \mathrm{df}=4$} \\
\cline { 2 - 5 } & $\begin{array}{c}\text { I can't } \\
\text { remember }\end{array}$ & 0 & 2 & 0 & \\
\hline
\end{tabular}

Missing values were not computed for this statistics. \#Only 193 respondents responded to the two cross-tabulated questions

\section{DISCUSSION}

This study was a survey of health professionals working in five major hospitals situated within the metropolitan city of Sokoto, Nigeria. This study had provided fresh data on the prevalence, sources and purpose of use of NOAs among health professionals in this geographical area.

The prevalence rate of the use of self-prescribed NOAs in this study was $85.4 \%$. This rate is far higher than that reported in some previous studies $[16,20]$. In fact, some $(10.7 \%)$ of our study subjects reported the use of self-prescribed NOAs some days prior to the time of participation in this study. This may suggest that some of subjects in this study were active users of self-prescribed NOAs.

Paracetamol, an OTC drug, was the most commonly (79\%) self-prescribed NOAs among the subjects in this study [10]. However, prescription-only medications like diclofenac, celecoxib, and piroxicam were found to be selfprescribed by some of the subjects. This reveals that some of the surveyed health professionals engaged themselves in irrational use of NOAs. 
The most popular purpose for the use of self-prescribed NOAs by the subjects was for the relief of headaches. Other purposes for its use were also noted, and they include relief of muscle pains, inflammation, toothache, menstrual pain, joint pain, fever and others. Similar reports on analgesic use had also been documented among health professionals in Southwestern Nigeria [16].

The sources where the subjects procured self-prescribed NOAs were diverse; these sources ranged from the drug hawkers, to the patent medicine stores. Indeed, it is interesting to note that the patent medicine stores and the hospital pharmacies were the top two sources where self-prescribed NOAs were got from. In a similar study done in Malaysia [20], the hospital pharmacy was also reported to be a major source for the procurement of self-prescribed medications among health professionals, and the main reason behind its frequent utilization was because of their easy accessibility to medications in the hospital pharmacy.

Although the NOAs had been reported to have good safety profile; Their chronic use or acute overdose could cause systemic toxicity - bringing about damage to the renal and cardiovascular systems [25-27]. For instance, in the UK and Australia, about $25 \%$ of all OTC analgesic users found to have consumed an overdose of NOAs. Also, it was found that one-third of OTC NOAs users had contraindications for its use, and/or were currently on medications that could interact with NOAs [28,29]. It is alarming that $6.8 \%$ of the self-prescribers of NOAs in this study had been treated for NOA overdose. This fact establishes the need for followup on the health professionals with histories of overdose of self-prescribed NOAs, as this will prevent them from developing any possible complications that could arise from NOA overdose.

The irrational use of drugs, such as self-prescribing, needs to be strongly discouraged among the Nigerian public. This practice has been found to be popular among health professionals [16-22]. The health professionals are supposed to be more rational in their use of drugs; however, many of them are not [16-22]. This is a serious public health issue which calls for urgent attention. The authors would like to recommend the enforcement of stricter regulations regarding access to drugs among health professionals in Sokoto, Nigeria; this could discourage them from self-prescribing NOAs. Also, drug regulatory agencies need to pay more attention to the strict monitoring of drug dispensing in hospital pharmacies and in local communities.

This study has its limitations. This study did not enquire into the NOAs that were consumed in overdose among the study subjects. Also, the study subjects were not asked if they have any known contraindication to the use of NOAs before its self-prescription. This suggests the need for a study to explore these research gaps.

\section{CONCLUSIONS}

The use of self-prescribed NOAs was highly prevalent among the health professionals in Sokoto metropolis, Nigeria. The purposes for which these drugs were self-prescribed were diverse; however, the most common purpose for the self-prescribing was for the relief from headaches.
The patent medicine stores and the hospital pharmacies were the most common sources for the procurement of selfprescribed NOAs. More efforts need to be made to curb irrational use of drugs among health professionals, as well as among the entire public.

\section{REFERENCES}

1. Paulo LC, Zanine AC. Automedicacao no Brasil. Rev Assoc Med Bras 1988;34:69-75.

2. Cooper RJ. Over-the-counter medicine abuse - a review of the literature. J Subst Use 2013;18(2):82-107.

3. World Health Organization: Guidelines for the regulatory assessment of Medicinal Products for use in self-medication 2000. Available: http://apps.who.int/medicinedocs/pdf/s2218e.pdf. [Last assessed on November 12, 2017].

4. Runciman WB, Roughead EE, Semple SJ, Adams RJ. Adverse drug events and medications error in Australia. Int J Qual Health Care 2003;

5. Singh G. Recent considerations in nonsteroidal anti-inflammatory drug gastropathy. Am J Med 1998; 105(1B):31S-38S.

6. Garcia Rodriguez LA, Hernandez-Diaz S. Relative risk of upper gastrointestinal complications among users of acetaminophen and NSAIDs. Epidemiol. 2001;12:570-6.

7. Hussain A, Khanum A. Self-medication among university student of Islamabad, Pakistan; A preliminary study. Southern Med Review 2008;1(1):14-6.

8. Patil SB, Vardhamane SH, Patil BV, Santoshkumar J, Binjawadgi AS, Kanaki AR. Self-medication practice and perceptions among undergraduate medical students: A cross-sectional study. J Clin Diagn Res. 2014; 8(12):HC20-HC23.

9. Agaba EI, Agaba PA, Wigwe CM. Use and abuse of analgesics in Nigeria: a community survey. Niger J Med. 2004;13(4):379-82.

10. Cooper RJ. Over-the-counter medicine abuse - a review of the literature. J Subst Use. 2013;18(2):82-107.

11. Cohen JP, Paquette C, Cairns CP. Switching prescription drugs to over the counter. BMJ 2005;330(7481):39-41.

12. Dale Ola, Borchgrevink PC, Fredheim OMS, Mahic M, Romundstad $\mathrm{P}$, Skurtveit S. Prevalence of use of non-prescription analgesics in the Norwegian HUNT3 population: Impact of gender, age, exercise and prescription of opioids. BMC Public Health 2015,15:461.

13. Jones A. Over-the-counter analgesics: a toxicologic perspective. Am J Therap. 2002;9(3):245-7.

14. Yoon E, Babar A, Choudhary M, Kutner M, Prysopoulos N. Acetaminophen-inducde hepatotoxicity: a comprehensive update. J Clin Transl Hepatol. 2016;4(2):131-42.

15. Omolase CO, Adeleke OE, Afolabi AO, Afolabi OT. Self medication amongst general outpatients in a Nigerian community hospital. Ann Ib Postgrad Med. 2007;5(2):64-7.

16. Babatunde OA, Fadare JO, Ojo OJ, Durowade KA, Atoyebi OA, Ajayi PO, Olaniyan T. Self-medication among health workers in a tertiary institution in South-west Nigeria. Pan Afr Med J. 2016;24:312.

17. Selley P. Self-prescribing by doctors. Health Trends. 1988;20(4):128-9.

18. Guille C, Sen Srijan. Prescription drug use and self-prescription among training physicians. Arch Intern Med. 2012;172(4):371-2.

19. Fadare J, Desalu O. Self-prescription practices by Nigerian medical doctors. S Afr Fam Pract. 2014;56(5):253-7.

20. Ali AN, Kai JTK, Keat CC, Dhanaraj SA. Self-medication practices among health care professionals in a private university, Malaysia. Int Curr Pharm J. 2012;1(10):302-10.

21. Barros ARR, Griep RH, Rotenberg L. Self-medication among nursing workers from public hospitals in Rio de Janeiro, Brazil. Rev Latino-am Emfermagem. 2009;17(6):1015-22.

22. Galvan MR, Pai DD, Echevarria-Guanilo ME. Self-medication among health professionals. REME - Rev Min Enferm 2016; 20:e959.

23. Wikipedia: the free encyclopedia [Internet]. St Petersburg (FL): Wikimedia Foundation, Inc. Sokoto [Updated 2017, June; cited 2017 November 18]; [1 screen]. Available from: https://en.m.wikipedia. org/wiki/Sokoto

24. Leslie K. Surveying sampling. New York: John Wiley and Sons, Inc; 1965. 
25. Runciman WB, Roughead EE, Semple SJ, Adams RJ. Adverse drug events and medications error in Australia. Int J Qual Health Care 2003; 15(Suppl 1):149-59.

26. Singh G. Recent considerations in nonsteroidal anti-inflammatory drug gastropathy. Am J Med 1998; 105(1B):31S-38S.

27. Garcia Rodriguez LA, Hernandez-Diaz S. Relative risk of upper gastrointestinal complications among users of acetaminophen and NSAIDs. Epidemiol. 2001;12:570-6.
28. French DP, James DH. Reasons for the use of mild analgesics among English students. Pharm World Sci 2008; 30(1):79-85.

29. Stostic R, Dunagan F, Palmer H, et al. Responsible self-medication: Perceived risks and benefits of over-the-counter analgesic use. Int Pharm Pract. 2011;19(4):236-45. 